\title{
Effect of thrombelastography on timing of coronary artery bypass grafting
}

\author{
ZHIYUAN YANG, ZHOULIANG XIE, XUELIANG PEI, XIAOQIANG QUAN and DEGUANG FENG \\ Department of Cardiovascular Surgery, Henan Provincial People's Hospital, Zhengzhou, Henan 450003, P.R. China
}

Received August 31, 2017; Accepted March 28, 2018

DOI: $10.3892 /$ etm.2018.6202

\begin{abstract}
The guiding value of thrombelastography (TEG) on the selection of surgical timing for patients scheduled for coronary artery bypass grafting (CABG) was investigated. A total of 90 subjects with acute coronary syndrome (ACS) treated between February 2014 and December 2016 in Henan Provincial People's Hospital were recruited. The patients received dual antiplatelet therapy (DAPT) and were scheduled for CABG. Subjects were randomly allocated into two groups, TEG group $(n=45)$ and non-TEG group $(n=45)$. Patients in the TEG group withheld medications at $24 \mathrm{~h}$ prior to surgery and received TEG examination. Based on maximum amplitude of adenosine diphosphate $\left(\mathrm{MA}_{\mathrm{ADP}}\right)$, subjects were further grouped into three sub-groups with $\mathrm{MA}_{\mathrm{ADP}}<35 \mathrm{~mm}, 35-50 \mathrm{~mm}$, and $>50 \mathrm{~mm}$, and accordingly received $C A B G$ within 1 day, 3-5 days and 5 days later, respectively. Subjects in the control group (non-TEG group) received $C A B G$ 5-7 days after medication withdrawal. Chest drainage volume within $24 \mathrm{~h}$ after surgery and red blood cell transfusion during perioperative period were compared. Other recorded parameters were incubation period, intensive care unit length of stay, hospital stay, incidence of 30-day adverse events and readmission rate. The average waiting time before CABG for patients of TEG group was shorter compared with the commonly recommended time. The red blood cell transfusions during perioperative period of subjects in TEG group and non-TEG group were significantly different $(\mathrm{P}=0.23)$. The median hospital stay of subjects in TEG group was shorter than that of non-TEG group $(\mathrm{P}=0.037)$. The bleeding amount of patients in TEG group was $220.16 \pm 80.56 \mathrm{ml}$, which was significantly lower than that of non-TEG group (435.29 \pm 90.16$)$. The difference was statistically significant $(\mathrm{P}=0.032)$. The results suggested that TEG assay-based evaluation of platelet function for patients
\end{abstract}

Correspondence to: Dr Zhouliang Xie, Department of Cardiovascular Surgery, Henan Provincial People's Hospital, 7 Weiwu Road, Zhengzhou, Henan 450003, P.R. China

E-mail: xiezhouliang2016@163.com

Key words: thrombelastography, coronary artery bypass grafting, surgical timing scheduled for CABG reasonably guides surgeons with appropriate surgical timing and reduces the amount of time patients wait to be treated.

\section{Introduction}

Dual antiplatelet therapy (DAPT) has been considered of high value in relieving the hypercoagulable states in patients with acute coronary syndrome (ACS) $(1,2)$. However, for patients scheduled for off-pump coronary artery bypass grafting (CABG), DAPT poses strong risk for perioperative bleeding in patients with CABG (3). Moreover, consumption of coagulation factor during cardiopulmonary bypass, dilution of fibrinogen and platelets, combined with other risk factors such as heparin and decreased body temperature, all result in depression on coagulation function, thus increasing the risk of perioperative bleeding, blood transfusion, postoperative mortality and rate of complication (4).

There has been no consensus on the timing of ACS patients receiving DAPT treatment. Previous findings showed that there was no significant difference of bleeding event between ACS patients withholding clopidogrel $\leq 5$ or $>5$ days before PCI (5). While according to class I recommendation by American College of Cardiology Foundation/American Heart Association (ACCF/AHA), patients should withhold clopidogrel for 5 days before $\mathrm{CABG}$ in order to restore the platelet function (6). Whereas, Class IIb recommendation by expert team on blood conservation of Society of Thoracic Surgeons (STS) suggested that platelet function test should be performed, based on which the surgical timing will be determined for patients receiving DAPT treatment (7). Therefore, in the present study, platelet function was measured using a TEG5000 thrombelastograph analyzer and the surgical timing was determined based on the measured maximum amplitude of adenosine diphosphate $\left(\mathrm{MA}_{\mathrm{ADP}}\right)$ values.

\section{Materials and methods}

Clinical material. In total, 90 subjects (including 47 males and 43 females; aged 42 to 80 years; average age, $61.2 \pm 10.2$ years) with ACS treated from February 2014 to December 2016 in cardiothoracic surgery department of Henan Provincial People's Hospital (Zhengzhou, China) were recruited. The patients received DAPT and were scheduled for CABG. All the patients received regular DAPT treatment before surgery 
of aspirin (100 mg/day) and clopidogrel (75 mg/day) (aspirin was purchased from Chifeng Wanze Pharmaceutical Co., Ltd. (Chifeng, China; NMPN. H10940218); clopidogrel was purchased from Wuhan Wuyao Pharmaceutical Co. Ltd. (Wuhan, China; NMPN. H20123155). Subjects were randomly allocated into two groups, thrombelastography (TEG) group $(n=45)$ and non-TEG group $(n=45)$, respectively in order of admission, and 45 patients (hereinafter referred to as TEG group/study group) withheld medications $24 \mathrm{~h}$ before surgery and received TEG examination. The TEG group included 23 males and 22 females, aged 43 to 79 years (average age, $61.3 \pm 9.8$ years). The other 45 patients (including 24 males and 21 females; aged 42-80 years; average age, $61.2 \pm 11.3$ years) received surgery after 5-7 days of medication withdrawal. For the TEG group, based on $\mathrm{MA}_{\mathrm{ADP}}$, subjects were further grouped into 3 sub-groups with $\mathrm{MA}_{\mathrm{ADP}}<35 \mathrm{~mm}, 35-50 \mathrm{~mm}$, and $>50 \mathrm{~mm}$, respectively, then accordingly, received CABG within 1 day, 3-5 days and 5 days after withdrawal. The patients were treated with off-pump CABG under general anesthesia. Heparin was given routinely for antithrombotic use.

Exclusion criteria for the study were: Patients that received emergency surgery after failing percutaneous coronary intervention; patients in need of either valve repair or valve replacement; patients with hematocrit $(\mathrm{PCV})<30 \%$; patients with coagulation disorders, renal insufficiency (creatinine clearance rate $<30 \mathrm{ml} / \mathrm{min}$ ), or viral hepatitis.

The study protocol was reviewed and approved by the ethics committee of Henan Provincial People's Hospital. The patients and families were fully informed of the study and signed the informed consent. No statistically significant difference was found between the two groups regarding age, sex ratio, prevalence of hypertension, diabetes, medical history of myocardial infarction (MI), preoperative ejection fraction and preoperative drug use $(\mathrm{P}>0.05)$. The general preoperative clinical data of the two groups of patients are presented in Table I.

Examination methods. A TEG 5000 thrombelastograph analyzer (Haemoscope Corporation, Niles, IL, USA) was used for the examination with ADP as inducer. The analyzer was operated under normal conditions, and relevant reagents and the instrument were operated as per instructions (Fig. 1). For the heparinized blood samples, at least $3 \mathrm{ml}$ peripheral blood was collected with heparinized anticoagulant tube followed by adequate stirring. Samples were sent for testing immediately. Examination were completed within $3 \mathrm{~h}$ after sample collection. For the TEG test results, $\mathrm{MA}_{\mathrm{ADP}}$, was recorded. Patients of TEG group were tested after $24 \mathrm{~h}$ of medication withdrawal. Based on the screening results of $\mathrm{MA}_{\mathrm{ADP}}$, patients of TEG group were further grouped into three sub-groups with $\mathrm{MA}_{\mathrm{ADP}}<35 \mathrm{~mm}$ (patients with platelet hyperreactivity), $35-50 \mathrm{~mm}$ (patients with medium platelet activity), and $>50 \mathrm{~mm}$ (patients with platelet hyporeactivity), respectively. Accordingly, subjects of the 3 sub-groups received CABG within 1 day, 3-5 days and 5 days after withdrawal. Patients in the control group commonly received surgery 5-7 days after medication withdrawal. Platelet inhibition rate induced by AA and ADP was calculated by computer software. At the same time, MA-Thrombin, MA induced by AA (MA-AA), MA induced by $\mathrm{ADP}\left(\mathrm{MA}_{\mathrm{ADP}}\right)$ were recorded.
Observation parameter. Chest drainage volume within $24 \mathrm{~h}$ (primary endpoint) and red blood cell transfusion in the perioperative period (secondary endpoint) were compared. Incubation period, intensive care unit (ICU) length of stay (LOS), hospital stay, incidence of 30-day adverse events, the amount of bleeding and readmission rate of the subjects in the two groups were reported.

Statistical analysis. IBM SPSS Statistics 21 software (IBM Corp., Armonk, NY, USA) was used to analyze the data. Quantitative data are described with difference between the two groups as mean \pm standard deviation, and assessed using $\mathrm{t}$-test. Numeration data variables were expressed as frequencies and percentages and performed with $\chi^{2}$ test to compare the difference. The one-way analysis of variance (ANOVA) with the least significant difference test was used to correct the variables. Count data were expressed by percentage (\%) and assessed with $\chi^{2}$ test. Difference with $\mathrm{P}<0.05$ was considered statistically significant.

\section{Results}

Waiting time before surgery for TEG group. Based on screening results of $\mathrm{MA}_{\mathrm{ADP}}$, patients of the TEG group for elective CABG were grouped into three sub-groups with $\mathrm{MA}_{\mathrm{ADP}}<35 \mathrm{~mm}$, $35-50 \mathrm{~mm}$, and $>50 \mathrm{~mm}$, respectively. Accordingly, subjects of 3 sub-groups received CABG within 1 day, 3-5 days and 5 days after withdrawal. Patients in the control group commonly received surgery 5-7 days after medication withdrawal. The average waiting time of patients in TEG group before CABG was 3.2 days. The detailed screening results of $\mathrm{MA}_{\mathrm{ADP}}$ and waiting time prior surgery of the 3 sub-groups of patients are shown in Fig. 2. Among patients of TEG group with $\mathrm{MA}_{\mathrm{ADP}}$ $<35 \mathrm{~mm}$, one patient received surgery earlier than scheduled. The matching rate between scheduled and actual waiting time was $86.67 \%$ (13/15). Among patients in TEG group with $\mathrm{MA}_{\mathrm{ADP}}$ of $35-50 \mathrm{~mm}$ scheduled to receive elective CABG within 3-5 days, two received surgery earlier than scheduled, resulting in a matching rate between scheduled and actual waiting time of $90.47 \%$ (19/21). Among patients with $\mathrm{MA}_{\mathrm{ADP}}$ $>50 \mathrm{~mm}$ and scheduled to receive CABG within 1 day, four patients received surgery after the scheduled time, resulting in a matching rate between scheduled and actual waiting time of $44.44 \%(4 / 9)$.

Comparison of the 24-h chest drains after surgery between the TEG and non-TEG groups. Statistical analysis was conducted with ANOVA-corrected variables and the results showed that there was no significant difference of the median 24-h chest drain volumes of patients between the TEG and non-TEG groups (435 and $488 \mathrm{ml}$ for TEG and non-TEG group, respectively; $\mathrm{P}=0.287$ ). Further analysis revealed that among patients of the three $\mathrm{MA}_{\mathrm{ADP}}$-based sub-groups of the TEG group, the 24-h postoperative chest drain volume of patients receiving surgery after 5 days was higher than those receiving CABG in 3-5 days, which was higher than those received within 1 day. However, no statistical difference was detected by comparing the chest drains of the three sub-groups $(\mathrm{P}=0.532)$. Detailed results are presented in Fig. 3. 
Table I. General preoperative condition of the two groups of patients undergoing CABG.

\begin{tabular}{|c|c|c|c|c|c|}
\hline Items & $\begin{array}{l}\text { Total } \\
(\mathrm{n}=90)\end{array}$ & $\begin{array}{l}\text { TEG group } \\
(\mathrm{n}=45)\end{array}$ & $\begin{array}{l}\text { Non-TEG } \\
\text { group }(n=45)\end{array}$ & $\chi^{2} / \mathrm{t}$ & P-value \\
\hline Age (years, mean \pm SD) & $60.7 \pm 9.8$ & $61.2 \pm 9.9$ & $60.3 \pm 10.1$ & 0.945 & 0.31 \\
\hline Sex, n $(\%)$ & $47(52.22)$ & $23(51.11)$ & $24(53.33)$ & 0.845 & 0.34 \\
\hline Hypertension, n (\%) & $71(78.89)$ & $35(77.78)$ & $36(80.0)$ & 0.942 & 0.33 \\
\hline Diabetics, n (\%) & $38(42.22)$ & $19(42.22)$ & $20(44.44)$ & 0.415 & 0.55 \\
\hline MI history, n (\%) & $29(32.22)$ & $15(33.33)$ & $14(31.11)$ & 0.428 & 0.52 \\
\hline Preoperative ACS, n (\%) & $37(41.11)$ & $19(42.22)$ & $18(40.0)$ & 0.275 & 0.74 \\
\hline Ejection fraction (\%, mean) & $52.3 \pm 12.1$ & $51.3 \pm 12.2$ & $53.4 \pm 12.1$ & 0.439 & 0.54 \\
\hline $\begin{array}{l}\text { Unfractionated heparin } \\
\text { ( } 24 \text { h before surgery), n (\%) }\end{array}$ & $31(34.44)$ & $15(33.33)$ & $16(57.78)$ & 0.117 & 0.92 \\
\hline ACEIs/ARBs, n (\%) & $62(68.89)$ & $30(66.67)$ & $32(71.11)$ & 0.029 & 0.86 \\
\hline$\beta$-blocker, n (\%) & $68(75.56)$ & $33(73.33)$ & $35(77.77)$ & 0.569 & 0.51 \\
\hline Statins, n (\%) & $9(10.0)$ & $4(8.89)$ & $5(11.11)$ & 0.023 & 0.48 \\
\hline PPIs, n (\%) & $9(10.0)$ & $4(8.89)$ & $5(11.11)$ & 0.339 & 0.75 \\
\hline Pre-operative INR & $0.91 \pm 0.18$ & $0.93 \pm 0.21$ & $0.94 \pm 0.15$ & 0.328 & 0.78 \\
\hline APTT (sec) & $29.42 \pm 2.13$ & $28.72 \pm 2.51$ & $28.62 \pm 2.25$ & 0.143 & 0.89 \\
\hline
\end{tabular}

CABG, coronary artery bypass surgery; TEG, thrombelastography; MI, myocardial infarction; ACS, acute coronary syndrome; ACEI, angiotension converting enzyme inhibitors; ARB, angiotensin receptor blocker; PPI, proton pump inhibitors; INR, international normalized ratio; APTT, activated partial thromboplastin time.

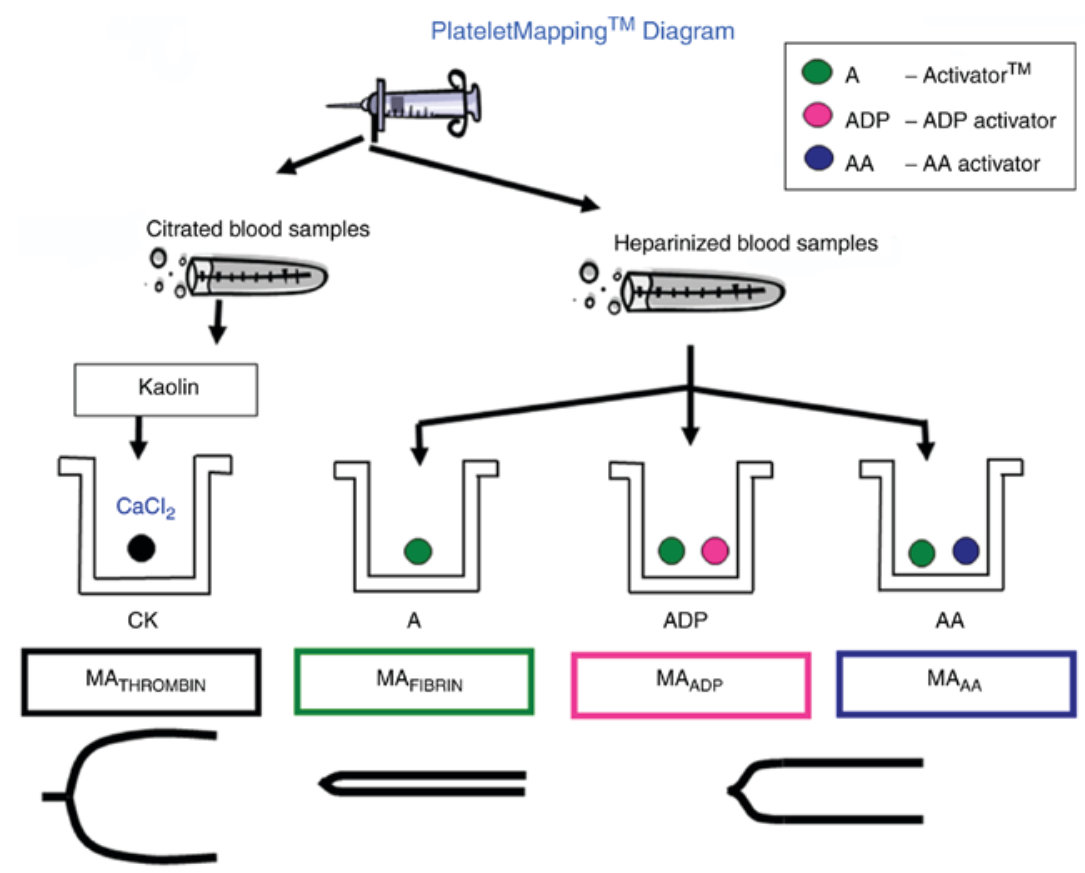

Figure 1. Schematic illustration of TEG platelet measurement. Different activators were used to detect heparinized blood samples. TEG, thrombelastography; $\mathrm{MA}_{\mathrm{ADP}}$, maximum amplitude of adenosine diphosphate.

Comparison of red cell transfusion during perioperative period between patients in TEG and non-TEG groups. No statistically significant difference was detected between TEG and non-TEG groups by comparing the average red blood cell transfusion volumes during perioperative period, which were 494.7 and $554.2 \mathrm{ml}$, respectively $(\mathrm{P}=0.23)$. With variables being corrected with ANOVA test, the average red blood cell transfusion volumes during perioperative period of TEG and non-TEG groups were 495.2 and $555.3 \mathrm{ml}$, respectively. No statistically significant difference was detected with bilateral U-test $(\mathrm{P}=0.06)$.

Comparison of clinical endpoint events between patients in TEG and non-TEG groups. The median hospital stay 
Table II. Comparison of clinical endpoint events between patients in TEG and non-TEG groups.

\begin{tabular}{lccc}
\hline Item & $\begin{array}{c}\text { TEG group } \\
(\mathrm{n}=45)\end{array}$ & $\begin{array}{c}\text { Non-TEG group } \\
(\mathrm{n}=45)\end{array}$ & $\begin{array}{c}\chi^{2 / \mathrm{t} \text { value }} \\
\text { P-value }\end{array}$ \\
\hline Perioperative chest drain (ml, median) & 438 & 489 & 1.037 \\
Incubation period (hour, median) & 21 & 22 & 0.835 \\
Hospital stay (day, median) & 24 & $32^{\mathrm{a}}$ & 2.076 \\
ICU length of stay (day, median) & 2 & 2 & 0.843 \\
Second thoracotomy, $(\%)$ & $0(0)$ & $0(0)$ & 0.081 \\
30-day mortality, $(\%)$ & $0(0)$ & 0.04 \\
30-day readmission rate, $\mathrm{n}(\%)$ & $7(15.56)$ & 0.47 \\
Amount of bleeding & $220.16 \pm 80.56$ & $435.29 \pm 90.16^{\mathrm{a}}$ & 1.00 \\
\hline
\end{tabular}

${ }^{\mathrm{a}} \mathrm{P}<0.05$. TEG, thrombelastography; ICU, intensive care unit.

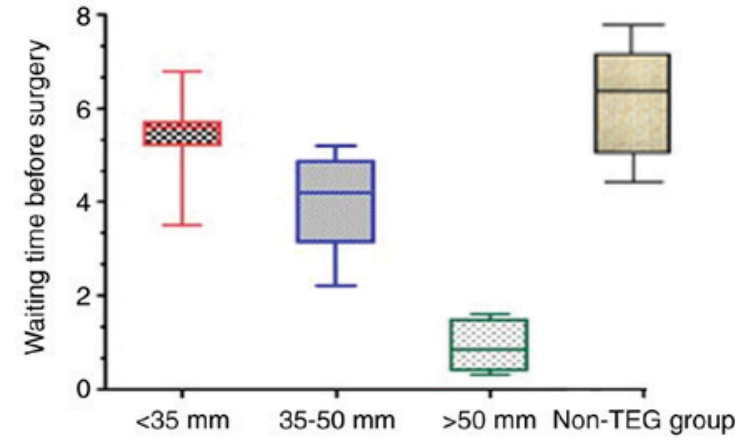

Figure 2. Box-plot indicating the scheduled and actual waiting time of patients in three sub-groups grouped by $\mathrm{MA}_{\mathrm{ADP}}$ before $\mathrm{CABG}$ and non-TEG group. $\mathrm{MA}_{\mathrm{ADP}}<35 \mathrm{~mm}$, the waiting time more than 5 days; $35 \mathrm{~mm} \leq \mathrm{MA}_{\mathrm{ADP}}$ $<50 \mathrm{~mm}$, the waiting time 3-5 days; $\mathrm{MA}_{\mathrm{ADP}} 50 \mathrm{~mm}$, the waiting time 1 day. $\mathrm{MA}_{\mathrm{ADP}}$, maximum amplitude of adenosine diphosphate; CABG, coronary artery bypass surgery; TEG, thrombelastography.

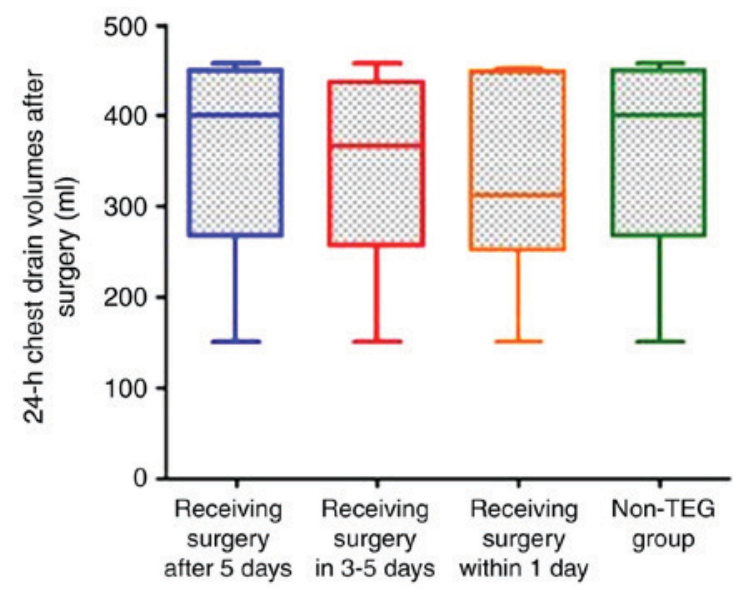

Figure 3. Box-plot indicating the chest drainage volume of patients in TEG and non-TEG groups. No statistical difference is observed by comparing the chest drains between the two groups $(\mathrm{P}=0.287)$. In addition, no statistically significant difference is found in the chest drains of patients of three sub-groups in TEG group were comparable $(\mathrm{P}=0.532)$. TEG, thrombelastography.

of patients in TEG group was 24 days, significantly shorter than that in non-TEG group $(\mathrm{P}=0.037)$. The bleeding amount of patients in TEG group was $220.16 \pm 80.56 \mathrm{ml}$, which was

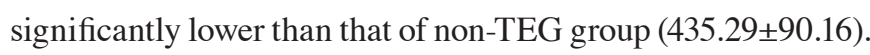
The difference was statistically significant $(\mathrm{P}=0.032)$. No statistically significant differences were found by comparing the perioperative chest drains, incubation period, ICU LOS, 30-day mortality, 30-day readmission rate $(\mathrm{P}>0.05)$. Detailed results are listed in Table II.

\section{Discussion}

Perioperative use of antiplatelet therapy is important for patients undergoing CABG. DAPT combining two medications of different mechanisms, aspirin with clopidogrel, is the most common antiplatelet therapy for patients with ACS. Specifically, with aspirin mainly inhibiting COX-1 (cyclooxygenase 1) by inhibiting the platelet thrombus formation and clopidogrel inhibiting the P2Y receptor on platelets, both medications irreversibly inhibit the platelet function $(8,9)$. Therefore, for ACS patients undergoing CABG surgery, reasonable selection of surgical timing and monitoring of platelet function is important to reduce perioperative bleeding, postoperative morbidity and mortality. Latest comparison of guidelines showed that patients taking clopidogrel are mostly recommended to have the surgery after 5 days of medication withdrawal. However, considering the individual difference in clopidogrel metabolism, platelet function in some patients may have already restored within 5 days of medication withdrawal. With such fact taken into consideration, preoperative monitoring of platelet function provides significant clinical value for selecting surgical time points, which is also considered as a safer approach $(10,11)$.

TEG analyzer is a monitor recording dynamic processes including blood coagulation, platelet aggregation, coagulation and fibrinolysis. It has become an important indicator of blood coagulation function during liver transplantation, and bypass surgery. It has been widely used in the assessment of antithrombotic therapy for coronary heart disease, platelet activity and antiplatelet effect in the world. But there are few studies in China. It is used in this study to evaluate the inhibition of platelets after treatment. Inhibition of platelet aggregation can be achieved by inhibition of cyclooxygenase pathway reducing the formation of TXA2, or inhibiting ADP receptor pathway. TEG platelet aggregation AA and ADP induced 
pathway is based on this. It was found that for PCI patients with high platelet reactivity detected by TEG, cTnI, CK-MB level increased significantly after PCI surgery. The incidence of clinical ischemia was increased 6 months after surgery, indicating that TEG is reliable for determining the high platelet reactivity caused by drug resistance after the operation.

Platelets play important roles in blood coagulation and determine approximately $80 \%$ of the strength of the clot. According to the response to antiplatelet therapy, patients can be categorized as platelet hyperreactivity (bleeding tendency), medium platelet activity, and platelet hyporeactivity (resistance to antiplatelet therapy) in clinic (12). Fitchett et al (13) performed blood platelet aggregation test using optical microscopy with varying inducers. Hyporeactivity to aspirin (aspirin resistance) was defined as platelet aggregation rate when taking aspirin $\geq 50 \%$ with $\mathrm{AA}$ as inducer, and hyporeactivity to clopidogrel (clopidogrel resistance) was defined as platelet aggregation of $\geq 70 \%$ with ADP as inducer. According to Fitchett et al, the $\mathrm{MA}_{\mathrm{ADP}}$ value was defined as $35 \mathrm{~mm}$ and $50 \mathrm{~mm}$ as transition point, TEG 5000 thrombelastograph analyzer was used to measure the platelet function and evaluate the medication-induced platelet inhibition. Based on the preoperative screening results of $\mathrm{MA}_{\mathrm{ADP}}$, patients in TEG group were allocated in to three sub-groups with $\mathrm{MA}_{\mathrm{ADP}}$ $<35 \mathrm{~mm}, 35-50 \mathrm{~mm}$, and $>50 \mathrm{~mm}$, respectively. Accordingly, patients of these three sub-groups received CABG within 1 day of medication withdrawal, after 3-5 days of medication withdrawal, and after 5 days of withdrawal, respectively. Patients of the TEG group waited for an average of 3.2 days before $\mathrm{CABG}, 36 \%$ shorter than 5 days as recommended by the guideline. Major parameters tested by TEG-measured platelet thrombelastogram included platelet inhibition rate (AA/ADP inhibition rate), $\mathrm{MA}_{\mathrm{ADP}}$ and $\mathrm{MA}_{\mathrm{CK}}$ (14). Platelet inhibition rate is a reference index of efficiency of antiplatelet drugs. Usually, inhibition of AA platelet stimulation $<50 \%$ or ADP $\%$ inhibition $<30 \%$ suggested inadequate antiplatelet efficacy; inhibition rate $>76 \%$ indicated relatively high platelet inhibition and clinical attention should be paid to potential risk of bleeding $(15,16)$. For patients taking antiplatelet medication before surgery, surgical timing can be selected according to the inhibition rate so as to better prevent the preoperative thrombus formation and intraoperative massive hemorrhage. $\mathrm{MA}_{\mathrm{ADP}}$ provides significant value by guiding the selection of surgical timing. Typically, for elective CABG, patients with $\mathrm{MA}_{\mathrm{ADP}}<35 \mathrm{~mm}$ should wait for more than 5 days before surgery; patients with $\mathrm{MA}_{\mathrm{ADP}}$ ranged $35 \mathrm{~mm}-50 \mathrm{~mm}$ should wait for 3-5 days prior to surgery; and patients with $\mathrm{MA}_{\mathrm{ADP}}>50 \mathrm{~mm}$ are allowed to receive the surgery on the same day as medication withdrawal $(4,17)$. In the present study, no significant difference was observed when comparing the postoperative $24-\mathrm{h}$ chest drains among the three TEG sub-groups. In addition, no statistically significant difference was found by comparing the 24 -h chest drains, perioperative average red blood cell transfusion volume, incubation period, ICU LOS, 30-day mortality, and 30-day readmission rate. These results showed that TEG-measured platelet function successfully guided the appropriate surgical timing, which resulted in comparable outcome and adverse event rates and reduced waiting time compared with patients received CABG 5 days after medication withdrawal. More importantly,
TEG-based platelet function measurement is featured with easy operation, high repeatability, and stable performance. Only trace amount of whole blood was required without any sample treatment. Results can be achieved within short test time down to $30 \mathrm{~min}$. Simultaneous categorized detection is possible for combined medication, providing test results free from effect of heparin drugs $(18,19)$. $\mathrm{MA}_{\mathrm{ADP}}$ value, $\mathrm{MA}_{\mathrm{AA}}$, $\mathrm{MA}_{\mathrm{CK}}$ and platelet inhibition rate measured by TEG are all objective parameters adequately reflecting the drug-induced platelet inhibition, which provides important value for patients in medical and surgical departments (20). Physicians may also benefit from the above-mentioned parameters by adjusting dosage to reduce risk of bleeding and thrombosis. Surgeons can guide the surgical and postoperative examination according to the indexes above so as to reduce the risk of perioperative bleeding and incidence of complications.

In summary, TEG-based platelet function evaluation for patient elective for $\mathrm{CABG}$ can reasonably guide the surgeons in surgical timing and reduce the waiting time prior to operation, without significant increase of postoperative bleeding volume and blood transfusion volume, as well as postoperative incidence rate of adverse events.

\section{Acknowledgements}

Not applicable.

\section{Funding}

No funding was received.

\section{Availability of data and materials}

The datasets used and/or analyzed during the current study are available from the corresponding author on reasonable request.

\section{Authors' contributions}

ZY collected and analyzed the general data. ZX performed TEG test. XP and XQ recorded MA-thrombin, MA induced by AA, MADP. ZY and DF recorded and interpreted incubation period, intensive care unit (ICU) length of stay (LOS), hospital stay, incidence of 30-day adverse events, the amount of bleeding and readmission rate. All authors read and approved the final manuscript.

\section{Ethics approval and consent to participate}

The study protocol was reviewed and approved by the Ethics Committee of Henan Provincial People's Hospital. The patients and families were fully informed of the study and signed the informed consent.

\section{Consent for publication}

Not applicable.

\section{Competing interests}

The authors declare that they have no competing interests. 


\section{References}

1. Roffi M, Gencer B, Storey RF, Andreotti F and Patrono C: Clinical perspectives and pearls from the 2015 ESC NSTE-ACS guidelines. Curr Cardiol Rep 18: 48, 2016.

2. Yanagawa B, Ruel M, Bonneau C, Lee MM, Chung J, Al Shouli S, Fagan A, Al Khalifa A, White CW, Yamashita MH, et al: Dual antiplatelet therapy use by Canadian cardiac surgeons. J Thorac Cardiovasc Surg 150: 1548-1554.e3, 2015.

3. Barbieri L, Pergolini P, Verdoia M, Rolla R, Nardin M, Marino P, Bellomo G, Suryapranata H and De Luca G; Novara Atherosclerosis Study Group (NAS): Platelet reactivity in patients with impaired renal function receiving dual antiplatelet therapy with clopidogrel or ticagrelor. Vascul Pharmacol 79: 11-15, 2016.

4. Janssen PWA, Claassens DMF, Willemsen LM, Bergmeijer TO, Klein P and Ten Berg JM: Perioperative management of antiplatelet treatment in patients undergoing isolated coronary artery bypass grafting in Dutch cardiothoracic centres. Neth Heart J 25: 482-489, 2017.

5. Pilgrim T and Windecker S: Antiplatelet therapy for secondary prevention of coronary artery disease. Heart 100: 1750-1756, 2014.

6. Levine GN, Bates ER, Bittl JA, Brindis RG, Fihn SD, Fleisher LA, Granger CB, Lange RA, Mack MJ, Mauri L, et al: 2016 ACC/AHA guideline focused update on duration of dual antiplatelet therapy in patients with coronary artery disease: A report of the American College of Cardiology/American Heart Association Task Force on Clinical Practice Guidelines. J Thorac Cardiovasc Surg 152: 1243-1275, 2016.

7. van Diepen S, Fuster V, Verma S, Hamza TH, Siami FS, Goodman SG and Farkouh ME: Dual antiplatelet therapy versus aspirin monotherapy in diabetics with multivessel disease undergoing CABG: FREEDOM insights. J Am Coll Cardiol 69: $119-127,2017$

8. Verma S, Goodman SG, Mehta SR, Latter DA, Ruel M, Gupta M, Yanagawa B, Al-Omran M, Gupta N, Teoh H, et al: Should dual antiplatelet therapy be used in patients following coronary artery bypass surgery? A meta-analysis of randomized controlled trials. BMC Surg 15: 112, 2015.

9. Cheng JW: Ticagrelor: Oral reversible P2Y(12) receptor antagonist for the management of acute coronary syndromes. Clin Ther 34: 1209-1220, 2012.

10. Karon BS, Tolan NV, Koch CD, Wockenfus AM, Miller RS, Lingineni RK, Pruthi RK, Chen D and Jaffe AS: Precision and reliability of 5 platelet function tests in healthy volunteers and donors on daily antiplatelet agent therapy. Clin Chem 60: 1524-1531, 2014.
11. Tantry US, Bonello L, Aradi D, Price MJ, Jeong $\mathrm{YH}$, Angiolillo DJ, Stone GW, Curzen N, Geisler T, Ten Berg J, et al: Consensus and update on the definition of on-treatment platelet reactivity to adenosine diphosphate associated with ischemia and bleeding. J Am Coll Cardiol 62: 2261-2273, 2013.

12. Bomb R, Oliphant CS and Khouzam RN: Dual antiplatelet therapy after coronary artery bypass grafting in the setting of acute coronary syndrome. Am J Cardiol 116: 148-154, 2015.

13. Fitchett D, Eikelboom J, Fremes S, Mazer D, Singh S, Bittira B, Brister S, Graham J, Gupta M, Karkouti K, et al: Dual antiplatelet therapy in patients requiring urgent coronary artery bypass grafting surgery: A position statement of the Canadian Cardiovascular Society. Can J Cardiol 25: 683-689, 2009.

14. Dias JD, Norem K, Doorneweerd DD, Thurer RL, Popovsky MA and Omert LA: Use of thromboelastography (TEG) for detection of new oral anticoagulants. Arch Pathol Lab Med 139: 665-673, 2015.

15. James K, Bertoja E, O'Beirne J and Mallett S: Use of thromboelastography PlateletMapping to monitor antithrombotic therapy in a patient with Budd-Chiari syndrome. Liver Transpl 16: 38-41, 2010.

16. Ramakrishna H, Gutsche JT, Patel PA, Evans AS, Weiner M, Morozowich ST, Gordon EK, Riha H, Bracker J, Ghadimi K, et al: The year in cardiothoracic and vascular anesthesia: Selected highlights from 2016. J Cardiothorac Vasc Anesth 31: 1-13, 2017.

17. Hansson EC, Malm CJ, Hesse C, Hornestam B, Dellborg M, Rexius $\mathrm{H}$ and Jeppsson A: Platelet function recovery after ticagrelor withdrawal in patients awaiting urgent coronary surgery. Eur J Cardiothorac Surg 51: 633-637, 2017.

18. Tang XF, Han YL, Zhang JH, Wang J, Zhang Y, Xu B, Gao Z, Qiao SB, Chen J, Wu Y, et al: Comparing of light transmittance aggregometry and modified thrombelastograph in predicting clinical outcomes in Chinese patients undergoing coronary stenting with clopidogrel. Chin Med J (Engl) 128: 774-779, 2015.

19. Yao Y, Zhang JH, Tang XF, He C, Ma YL, Xu JJ, Song Y, Liu R, Meng XM, Song L, et al: Head to head comparison of two point-of-care platelet function tests used for assessment of on-clopidogrel platelet reactivity in Chinese acute myocardial infarction patients undergoing percutaneous coronary intervention. Chin Med J (Engl) 129: 2269-2274, 2016.

20. Bochsen L, Wiinberg B, Kjelgaard-Hansen M, Steinbrüchel DA and Johansson PI: Evaluation of the TEG platelet mapping assay in blood donors. Thromb J 5: 3, 2007.

This work is licensed under a Creative Commons Attribution-NonCommercial-NoDerivatives 4.0 International (CC BY-NC-ND 4.0) License. 